\title{
Ethanol-Mediated Facilitation of AMPA Receptor Function in the Dorsomedial Striatum: Implications for Alcohol Drinking Behavior
}

\author{
Jun Wang, ${ }^{1,2}$ Sami Ben Hamida, ${ }^{1}$ Emmanuel Darcq, ${ }^{1}$ Wenheng Zhu, ${ }^{1}$ Stuart L. Gibb, ${ }^{1}$ Maria Fe Lanfranco, ${ }^{1}$ \\ Sebastien Carnicella, ${ }^{1,2}$ and Dorit Ron ${ }^{1,2}$ \\ ${ }^{1}$ Ernest Gallo Research Center and ${ }^{2}$ Department of Neurology, University of California at San Francisco, Emeryville, California 94608
}

\begin{abstract}
We found previously that acute ex vivo as well as repeated cycles of in vivo ethanol exposure and withdrawal, including excessive voluntary consumption of ethanol, produces a long-lasting increase in the activity of NR2B-containing NMDA receptors (NR2BNMDARs) in the dorsomedial striatum (DMS) of rats (Wang et al., 2010a). Activation of NMDARs is required for the induction of long-term potentiation (LTP) of AMPA receptor (AMPAR)-mediated synaptic response. We therefore examined whether the ethanolmediated upregulation of NMDAR activity alters the induction of LTP in the DMS. We found that ex vivo acute exposure of striatal slices to, and withdrawal from, ethanol facilitates the induction of LTP in DMS neurons, which is abolished by the inhibition of NR2B-NMDARs. We also report that repeated systemic administration of ethanol causes an NR2B-NMDAR-dependent facilitation of LTP in the DMS. LTP is mediated by the insertion of AMPAR subunits into the synaptic membrane, and we found that repeated systemic administration of ethanol, as well as cycles of excessive ethanol consumption and withdrawal, produced a long-lasting increase in synaptic localization of the GluR1 and GluR2 subunits of AMPARs in the DMS. Importantly, we report that inhibition of AMPARs in the DMS attenuates operant self-administration of ethanol, but not of sucrose. Together, our data suggest that aberrant synaptic plasticity in the DMS induced by repeated cycles of ethanol exposure and withdrawal contributes to the molecular mechanisms underlying the development and/or maintenance of excessive ethanol consumption.
\end{abstract}

\section{Introduction}

Drug and alcohol (ethanol) addiction is a pathological form of learning and memory (Hyman et al., 2006; Kalivas and O'Brien, 2008). Long-term potentiation (LTP) of AMPA receptor (AMPAR)-mediated synaptic response, a cellular substrate of learning and memory (Bliss and Collingridge, 1993; Malenka and Nicoll, 1999), is modulated or triggered by exposure to drugs of abuse (Kauer and Malenka, 2007; Russo et al., 2010; Lüscher and Malenka, 2011; McCool, 2011). For example, in vivo cocaine exposure elicits NMDA receptor (NMDAR)-dependent LTP in the ventral tegmental area (Ungless et al., 2001), and aberrant synaptic plasticity has been shown to contribute to the development of compulsive drug seeking and taking (Kauer and Malenka, 2007; Russo et al., 2010; Lüscher and Malenka, 2011; McCool, 2011). The dorsal striatum, a subcortical brain region important for

\footnotetext{
Received June 7, 2012; revised Aug. 17, 2012; accepted Sept. 5, 2012.

Author contributions: J.W., S.C., and D.R. designed research; J.W., S.B.H., E.D., W.Z., S.L.G., M.F.L., and S.C. performed research; J.W., S.B.H., E.D., W.Z., S.L.G., and S.C. analyzed data; J.W., S.C., and D.R. wrote the paper.

This work was supported by funds provided by the State of California for medical research on alcohol and substance abuse through the University of California, San Francisco (D.R.), by NIAAA Grants R01AA/MH13438 (D.R.) and P50AA017072 (D.R., J.W.), and by Alcoholic Beverage Medical Research Foundation (ABMRF)/The Foundation for Alcohol Research (J.W.).

Correspondence should be addressed to Dorit Ron, 5858 Horton St., Suite 200, Emeryville, CA 94608. E-mail: dron@gallo.ucsf.edu.

S. Carnicella's present address: INSERM U836, Grenoble Institute of Neuroscience, Grenoble, France.

DOI:10.1523/JNEUROSCI.2783-12.2012

Copyright $\odot 2012$ the authors $\quad 0270-6474 / 12 / 3215124-09 \$ 15.00 / 0$
}

proper motor function (Graybiel et al., 1994), also plays an important role in behaviors that are associated with drug addiction (Yin and Knowlton, 2006). The principal cells of the dorsal striatum are medium spiny neurons (MSNs). Based on their projection targets, MSNs are divided into two groups: striatonigral and striatopallidal MSNs. The striatonigral MSNs project to the substantia nigra pars reticulata $(\mathrm{SNr})$ forming the direct pathway, whereas the striatopallidal MSNs project to the lateral globus pallidus giving rise to the indirect pathway. Activity of striatonigral MSNs stimulates whereas activity of striatopallidal MSNs inhibits rewarding behaviors (Durieux et al., 2009; Bateup et al., 2010; Hikida et al., 2010; Lobo et al., 2010; Beutler et al., 2011; Ferguson et al., 2011). The dorsal striatum can be also divided into two subregions: the dorsolateral striatum (DLS; equivalent of the putamen in human) and the dorsomedial striatum (DMS; equivalent of the caudate in human), which differ in connectivity, synaptic plasticity, and behavioral functions (Gerdeman et al., 2003; Voorn et al., 2004; Yin and Knowlton, 2006; Belin et al., 2009). The DMS is strongly implicated in the acquisition and expression of goal-directed behaviors (Yin and Knowlton, 2006; Corbit and Janak, 2010). We found previously that withdrawal from acute ex vivo ethanol exposure leads to long-term enhancement of NR2B-containing NMDAR (NR2B-NMDAR) activity in the dorsal striatum (Wang et al., 2007), and we observed that this enhancement occurs preferentially in the DMS but not the DLS (Wang et al., 2010a). We also showed that repeated systemic administration of ethanol, as well as cycles of voluntary excessive 
ethanol intake and withdrawal, results in a long-lasting increase in NMDAR activity in the DMS (Wang et al., 2010a). Activation of NMDARs is required for the induction of LTP in various brain regions such as the hippocampus and cortex (Bliss and Collingridge, 1993; Malenka and Nicoll, 1999) as well as in the dorsal striatum (Calabresi et al., 1992; Partridge et al., 2000; Shen et al., 2008). Therefore, we tested the hypothesis that repeated cycles of ethanol exposure and withdrawal induce long-lasting NMDARdependent neuroadaptations in AMPAR activity that may contribute to mechanisms underlying the expression and/or maintenance of excessive ethanol intake.

\section{Materials and Methods}

\section{Reagents}

Anti-GluR1 (04-855) and anti-GluR2 (MAB397) antibodies were obtained from Millipore. Anti-glyceraldehyde-3-phosphate dehydrogenase (GAPDH) (sc25778) antibody and all of the horseradish peroxidase (HRP)conjugated secondary antibodies were purchased from Santa Cruz Biotechnology. Enhanced chemiluminescence (ECL) reagents were from GE Healthcare. NuPAGE Bis-Tris precast gels were from Invitrogen. The bicinchoninic acid (BCA) protein assay kit was obtained from Pierce. Complete mini EDTA-free protease inhibitor cocktail was purchased from Roche. NMDA, AMPA, picrotoxin, sulpiride, and phosphatase inhibitor cocktails 1 and 2 were obtained from Sigma. (2R)-amino-5phosphonopentanoate (APV), 2,3-dioxo-6-nitro-1,2,3,4-tetrahydrobenzo $[f]$ quinoxaline-7-sulfonamide disodium salt (NBQX), $(\alpha R, \beta S)$ - $\alpha$-(4-hydroxyphenyl)- $\beta$-methyl-4-( phenylmethyl)-1piperidinepropanol hydrochloride (Ro 25-6981), cyclothiazide, and tetrodotoxin were purchased from Tocris Bioscience.

\section{Animals}

Male Sprague Dawley rats (14-28 d old) and male Long-Evans rats (2.5 months old) were purchased from Harlan Laboratories. Rats were housed under a $12 \mathrm{~h}$ light/dark cycle, with lights on at 7:00 A.M., and food and water available ad libitum. All animal procedures were approved by the Gallo Center Institutional Animal Care and Use Committee and were conducted in agreement with the National Research Council Guide for the Care and Use of Laboratory Animals.

\section{Electrophysiology}

Slice preparation. Slice preparation has been described previously (Wang et al., 2010a). Briefly, coronal sections of the striatum $(300 \mu \mathrm{m})$ were cut in an ice-cold solution containing the following (in mM): $40 \mathrm{NaCl}, 143.5$ sucrose, $4 \mathrm{KCl}, 1.25 \mathrm{NaH}_{2} \mathrm{PO}_{4}, 26 \mathrm{NaHCO}_{3}, 0.5 \mathrm{CaCl}_{2}, 7 \mathrm{MgCl}_{2}, 10$ glucose, 1 sodium ascorbate, and 3 sodium pyruvate, saturated with $95 \%$ $\mathrm{O}_{2}$ and $5 \% \mathrm{CO}_{2}$. Slices were then incubated in the same solution at $32^{\circ} \mathrm{C}$ for $45 \mathrm{~min}$ before being transferred to a chamber that contained an external solution composed of the following (in $\mathrm{mM}$ ): $125 \mathrm{NaCl}, 2.5 \mathrm{KCl}$, $2.5 \mathrm{CaCl}_{2}, 1.3 \mathrm{MgCl}_{2}, 1.25 \mathrm{NaH}_{2} \mathrm{PO}_{4}, 25 \mathrm{NaHCO}_{3}$, and 10 glucose, saturated with $95 \% \mathrm{O}_{2}$ and $5 \% \mathrm{CO}_{2}$. Slices were stored in the external solution at room temperature until use.

Whole-cell recording. NMDA-induced currents and AMPAR-mediated miniature EPSCs (mEPSCs) were measured as described previously (Wang et al., 2010a,b). AMPA-induced currents were measured as described by Borgland et al. (2006). Specifically, AMPA $(0.2 \mu \mathrm{M})$ was bath applied for $30 \mathrm{~s}$ in the presence of the AMPAR desensitization blocker cyclothiazide (100 $\mu \mathrm{M})$. NMDA/AMPA ratios were measured as described by Ungless et al. (2001). Briefly, evoked EPSCs that were mediated by both NMDARs and AMPARs ( EPSC $_{\mathrm{NMDA}+\mathrm{AMPA}}$ ) were first measured in neurons clamped at $+40 \mathrm{mV}$ and in the presence of $1.3 \mathrm{~mm}$ external $\mathrm{Mg}^{2+}$. Then, AMPARmediated EPSCs $\left(\right.$ EPSC $_{\text {AMPA }}$ ) were measured following a 5 min application of APV $(50 \mu \mathrm{M})$ that blocked NMDAR-mediated EPSCs $\left(\right.$ EPSC $\left._{\mathrm{NMDA}}\right)$. EP$\mathrm{SC}_{\mathrm{NMDA}}$ was obtained by digital subtraction of $\mathrm{EPSC}_{\mathrm{AMPA}}$ from $\mathrm{EPSC}_{\mathrm{NMDA}+\mathrm{AMPA}}$. The peak of $\mathrm{EPSC}_{\mathrm{NMDA}}$ was divided by the peak of EP$\mathrm{SC}_{\mathrm{AMPA}}$ to yield an NMDA/AMPA ratio. Electrodes $(4-6 \mathrm{M} \Omega$ ) contained the following (in mM): 115 cesium methanesulfonate, 15 HEPES, 0.6 EGTA, 8 TEA-Cl, 4 MgATP, $0.3 \mathrm{NaGTP}$, and $7 \mathrm{Na}_{2} \mathrm{CrPO}_{4}, \mathrm{pH}$ 7.2-7.3, with an osmolarity of $270-280 \mathrm{mOsm}$
Field potential recording. Extracellular field recordings were conducted as described by Yin et al. (2007) and Schotanus and Chergui (2008). Field EPSP/population spikes (PSs) were measured in the presence of $100 \mu \mathrm{M}$ picrotoxin to block $\mathrm{GABA}_{\mathrm{A}}$ receptors and a dopamine $\mathrm{D} 2$ receptor inhibitor, sulpiride $(20 \mu \mathrm{M})$, which suppresses the induction of long-term depression (Shen et al., 2008). fEPSP/PSs were blocked by the AMPAR antagonist NBQX (data not shown). LTP was induced by two trains of high-frequency stimulation (HFS) at an interval of $10 \mathrm{~s}$. Each train contained 100 pulses at $100 \mathrm{~Hz}$.

\section{Biochemical procedures}

DMS tissue collection and processing, synaptosomal membrane preparation, and Western blot analysis. The methods used herein have been described previously (Wang et al., 2010a).

DMS tissue collection and processing. DMS tissues were dissected and homogenized in ice-cold radio immunoprecipitation assay (RIPA) buffer containing $50 \mathrm{~mm}$ Tris-Cl, $5 \mathrm{~mm}$ EDTA, $120 \mathrm{~mm} \mathrm{NaCl}, 1 \% \mathrm{NP}-40,0.1 \%$ deoxycholate, $0.5 \%$ SDS, and protease and phosphatase inhibitor cocktails.

Synaptosomal membrane preparation. DMS tissues were homogenized in a glass homogenizer containing $500 \mu \mathrm{l}$ of ice-cold Krebs-sucrose buffer [containing (in mM) $125 \mathrm{NaCl}, 1.2 \mathrm{KCl}, 1.2 \mathrm{MgSO}_{4}, 1.2 \mathrm{CaCl}_{2}, 22$ $\mathrm{Na}_{2} \mathrm{CO}_{3}, 1.2 \mathrm{NaH}_{2} \mathrm{PO}_{4}, 10$ glucose, and 320 sucrose, $\left.\mathrm{pH} 7.4\right]$ in the presence of protease and phosphatase inhibitors. The homogenate was centrifuged at $1000 \times g$ for $10 \mathrm{~min}$ at $4^{\circ} \mathrm{C}$ to pellet heavy membranes and debris (P1). The supernatant (S1) was collected and centrifuged at $16,000 \times g$ at $4^{\circ} \mathrm{C}$ for $20 \mathrm{~min}$ to pellet the synaptosomal membrane fraction (P2). P2 was resuspended in $100 \mu$ l RIPA buffer. Protein concentration was determined using the BCA protein assay kit.

Western blot analysis. Samples were separated on NuPAGE 4-12\% Bis-Tris gradient gels. After an overnight transfer at $4^{\circ} \mathrm{C}$ onto nitrocellulose membranes, blots were blocked in $5 \%$ milk/TBST for $1 \mathrm{~h}$ before probing with anti-GluR1 (1:1000) or anti-GluR2 (1:1000) antibodies followed by HRP-conjugated secondary antibodies. GAPDH was used as a loading control. Immunoreactivity was detected using ECL plus. The optical density of the relevant immunoreactive band was quantified using the NIH Image 1.63 program.

\section{In vivo systemic administration of ethanol}

The procedure is similar to the one described previously (Wang et al., 2010a). Briefly, Sprague Dawley rats were administered intraperitoneally with ethanol $(20 \%, 2 \mathrm{~g} / \mathrm{kg})$ or saline once a day for 7 consecutive days. Sixteen hours after the seventh treatment, striatal slices containing the DMS were prepared for electrophysiological recordings, or DMS tissues were dissected out for biochemical measurements.

\section{Behavioral procedures}

Intermittent-access two-bottle choice procedure. The procedure is similar to the one described previously (Wang et al., 2010a). Briefly, Long-Evans rats were given $24 \mathrm{~h}$ concurrent access to 1 bottle of $20 \%$ ethanol (v/v) in water and 1 bottle of water starting at 11:00 A.M. on Monday, Wednesday, and Friday, with 24 or $48 \mathrm{~h}$ ethanol deprivation periods between the ethanol drinking sessions. The water and ethanol bottles were weighed after $24 \mathrm{~h}$ of access. Experiments started after a stable baseline of consumption was achieved (average of $6 \mathrm{~g} / \mathrm{kg}$ per $24 \mathrm{~h}$ ). The control groups had access to two bottles of water throughout the duration of the experiment.

Operant ethanol self-administration. Long-Evans rats were first trained to consume high levels of ethanol using the intermittent-access $20 \%$ ethanol two-bottle choice drinking procedure as described previously (Wang et al., 2010a). After achieving a stable baseline of intake, rats were trained to self-administer a $20 \%$ ethanol solution in an operant selfadministration chamber. After two to three nights in the chamber to allow acquisition of lever-press response for ethanol under Fixed Ratio 1 (FR1), operant sessions were conducted $5 \mathrm{~d}$ per week, with the schedule requirement increasing to Fixed Ratio 3 (FR3), and the length of session was shortened from 60 to $30 \mathrm{~min}$ over the first 2 weeks. Animals had ad libitum access to food and water in their home cages but not during the 30 min session of operant self-administration. After 1 month of training, surgery was conducted to implant cannulae.

Operant sucrose self-administration. Long-Evans rats were initially trained under FR1 using $8 \%$ sucrose (w/v) during two overnight sessions. 

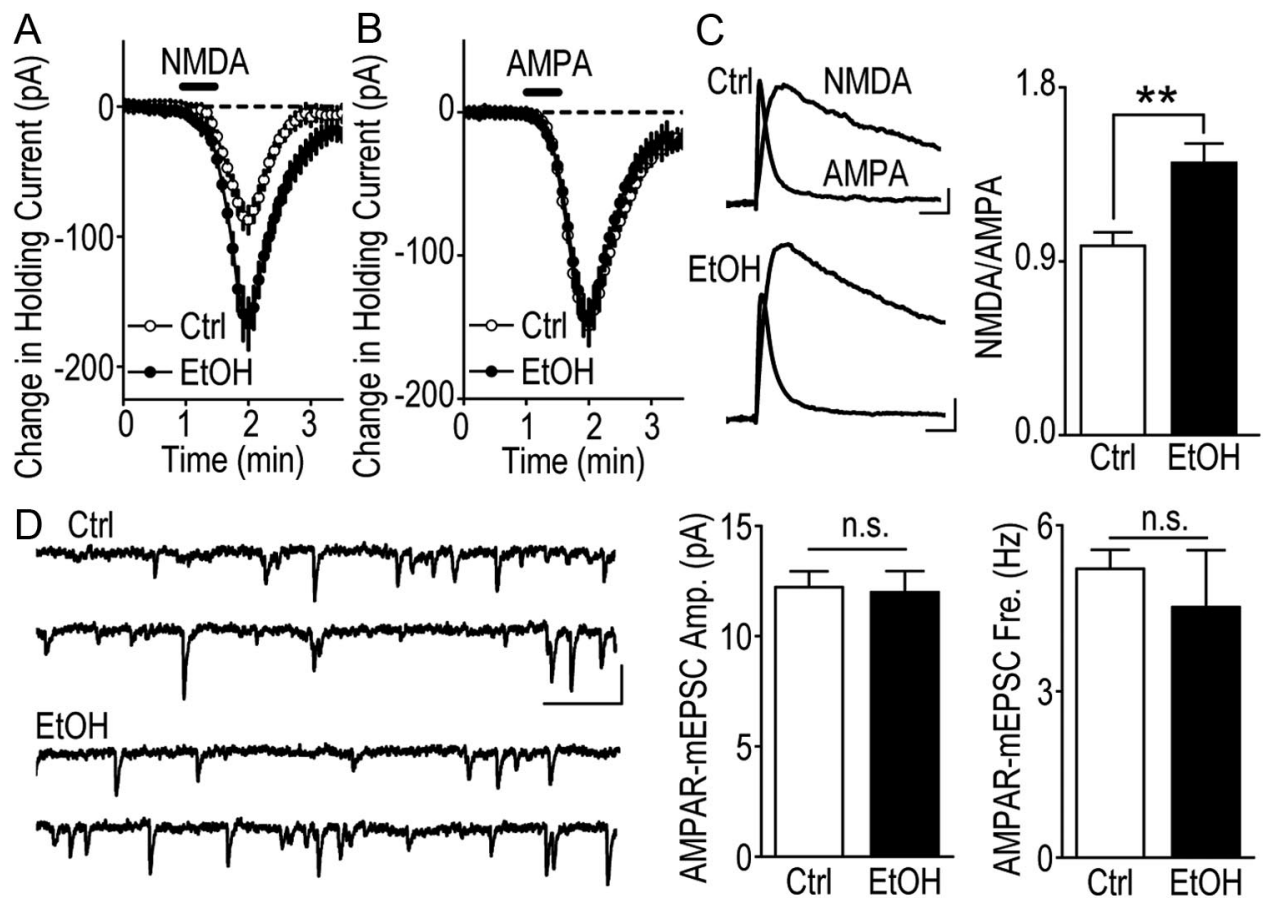

Figure 1. Ex vivo ethanol exposure and withdrawal upregulates NMDAR but not AMPAR activity. Striatal slices from Sprague Dawley rats were treated for $1 \mathrm{~h}$ with $40 \mathrm{~mm}$ ethanol, which was then washed out for 30 min before electrophysiological measurements. Control slices (Ctrl) were exposed to the same treatment but without ethanol (EtOH). $\boldsymbol{A}$, Ex vivo ethanol treatment causes an increase in NMDA-induced currents. Changes in holding currents in DMS neurons were measured after NMDA (10 $\mu \mathrm{m}, 30 \mathrm{~s})$ was bath applied to control and ethanol-treated slices. $n=8$ per group. $\boldsymbol{B}$, Ex vivo ethanol treatment does not alter AMPA-induced currents. Changes in holding currents were measured in DMS neurons after AMPA ( $0.2 \mu \mathrm{M}, 30 \mathrm{~s})$ was bath applied. $n=8$ per group. $\boldsymbol{C}$, Ex vivo ethanol treatment causes an increase in NMDA/AMPA ratio. Left, Sample traces of NMDAR-mediated and AMPAR-mediated EPSCs in control slices (top) and in ethanol-treated slices (bottom). Calibration: $30 \mathrm{~ms}, 30 \mathrm{pA}$. Right, Bar graph summarizing the mean of NMDA/AMPA ratios in control slices and ethanol-treated slices. ${ }^{* *} p<0.01(t$ test). $n=9$ (Ctrl) and $n=10$ (EtOH). $D, E x$ vivo ethanol treatment does not alter the amplitude or frequency of AMPAR-mediated mEPSCs (AMPAR-mEPSCs) in DMS neurons. Left, Sample traces of mEPSCs in control slices (top) and in ethanoltreated slices (bottom). Calibration: $0.2 \mathrm{~s}, 10 \mathrm{pA}$. Middle, right, Bar graph summarizing the mean amplitudes (middle) and frequencies (right) of AMPAR-mediated EPSCs in control and ethanoltreated slices. $n=10$ per group. n.S., Not significant.

The FR schedule was then increased to FR3, and the sucrose concentration was progressively decreased to $1.5 \%$, while the length of the session was shortened to $30 \mathrm{~min}$. These procedures were chosen to obtain leverpress activity similar to that observed in operant ethanol selfadministration. After 1 month of training, surgery was conducted to implant cannulae.

Cannulae implantation and treatment. Bilateral guide cannulae (26 gauge) were implanted in the DMS [1.2 mm anterior, $1.5 \mathrm{~mm}$ mediolateral, $4.2 \mathrm{~mm}$ ventral to bregma, according to Paxinos and Watson (2007)]. After $4 \mathrm{~d}$ of recovery, rats were returned to the self-administration training and were habituated to the microinjection procedure with three sham injections and one infusion of PBS. Fifteen minutes before the testing session, an AMPAR antagonist, NBQX ( 0.2 or $2 \mu \mathrm{g} / 1 \mu \mathrm{l}$ per side in PBS), or vehicle (PBS, $1 \mu \mathrm{l}$ per side) was infused bilaterally into the DMS using a $25 \mu$ l Hamilton syringe. The infusion speed was $0.5 \mu \mathrm{l}$ per minute, and the injectors were kept in position for an additional $2 \mathrm{~min}$. The lever presses for ethanol or sucrose were measured in operant self-administration chambers for $30 \mathrm{~min}$.

Histology. Rats implanted with cannulae were anesthetized by intraperitoneal injection of pentobarbital and transcardially perfused with $4 \%$ paraformaldehyde. Locations of cannulae were verified in $50 \mu \mathrm{m}$ coronal sections stained with thionin to allow visualization of probe tracks in the DMS. Only subjects with cannulae located within the DMS were included for statistical analysis.

\section{Statistical analysis}

All data are expressed as mean \pm SEM. The electrophysiological data were analyzed by normalizing the peak amplitudes of fEPSP/PSs to those during baseline ( $0-10 \mathrm{~min}$ before HFS). Data were analyzed using twoway ANOVA with repeated-measures (RM-ANOVA), followed by the Student-Newman-Keuls (SNK) post hoc test as described previously (Wang et al., 2010a). Biochemical data were analyzed by calculating the ratio of the intensity of the immunoreactive band of interest to GAPDH, and the resultant data were analyzed using an unpaired, two-tailed $t$ test. Behavioral data were analyzed using one-way RM-ANOVA, followed by the SNK test.

\section{Results}

Acute ex vivo ethanol exposure and withdrawal upregulates synaptic NMDAR, but not AMPAR, activity in the DMS

First, we examined whether ex vivo acute ethanol exposure and withdrawal alters both NMDAR and AMPAR activity in the DMS. To do so, striatal slices from Sprague Dawley rats were treated with $40 \mathrm{~mm}$ ethanol for $1 \mathrm{~h}$, and ethanol was washed out for 30 min before the activity of NMDARs and AMPARs were measured. Forty millimolar ethanol is widely used in slice recording experiments (Kang-Park et al., 2007; Xiao et al., 2009; Jeanes et al., 2011), and we showed previously that long-lasting enhancement of NMDAR activity in the DMS can be reliably detected in response to this relatively low concentration of ethanol (Wang et al., 2010a). We found that NMDA-induced currents are significantly higher in ethanol-treated slices than in controls (peak currents, $169.3 \pm 20.5 \mathrm{pA}$ for ethanol vs $86.4 \pm 9.1 \mathrm{pA}$ for control; $t_{(14)}=-3.70 ; p<0.01$; Fig. $1 A$ ). However, AMPAinduced currents were identical between ethanol-treated slices and control slices (peak currents, $156.3 \pm 16.0 \mathrm{pA}$ for ethanol vs $151.0 \pm 14.1 \mathrm{pA}$ for control; $t_{(14)}=-0.25 ; p>0.05$; Fig. $1 B$ ). Since NMDA-induced currents measure the activity of synaptic and extrasynaptic receptors, the enhanced NMDA current by acute ethanol exposure and withdrawal may result from an upregulation of either synaptic and/or extrasynaptic NMDARs. To assess whether synaptic NMDAR activity is altered following 

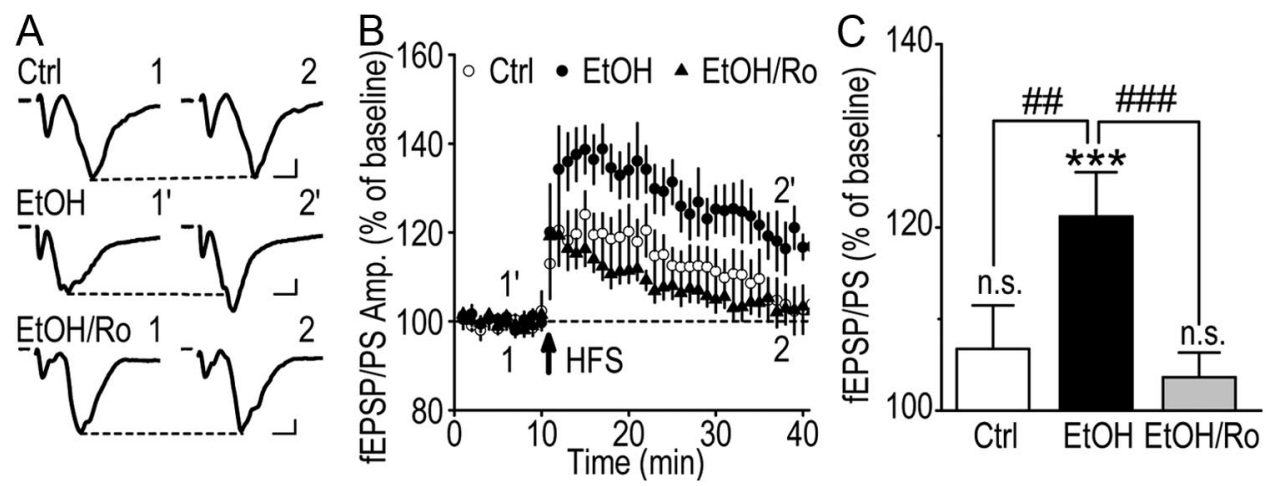

Figure 2. Ex vivo ethanol exposure and withdrawal facilitates the induction of LTP in an NR2B-NMDAR-dependent manner. Striatal slices from Sprague Dawley rats were treated with 40 mm ethanol for $1 \mathrm{~h}$, ethanol was washed out for $30 \mathrm{~min}$, and HFS was delivered in the absence (EtOH) or presence (EtOH/Ro) of Ro 25-6981 (0.5 $\mu \mathrm{m}$ ), in which Ro 25-6981 was present throughout the recording period. Control slices (Ctrl) were exposed to the same treatment but without ethanol or Ro 25-6981. $A$, Sample traces of fEPSP/PSs before (1, $1^{\prime}$ ) and after (2, $2^{\prime}$ ) HFS in Ctrl (top) as well as EtOH-treated (middle) and EtOH/Ro-treated (bottom) slices. Note that the peak of the fEPSP/PSs (the second downward waveform) increases after HFS in EtOH-treated slices, but not in Ctrl or EtOH/Ro-treated slices. The stimulus artifacts have been omitted for clarity. Calibration: $2 \mathrm{~ms}, 0.1 \mathrm{mV}$. B, Time course of fEPSP/PSs before and after HFS in Ctrl (white circles) as well as EtOH-treated (black circles) and EtOH/Ro-treated (triangles) slices. Note that HFS induced greater increases in fEPSP/PSs amplitude in EtOH-treated slices than in Ctrl and EtOH/Ro-treated slices. The numbers 1 , $1^{\prime}$, 2, and $2^{\prime}$ indicate time points where the sample traces in $A$ were selected. C, Bar graphs summarizing the mean amplitudes of fEPSP/PSs 20 -30 min after HFS in control (white bar), EtOH-treated (black bar) and EtOH/Ro-treated (gray bar) slices. n.S., $p>0.05$ for EPSCs at time point 2 versus time point 1 (SNK test); ${ }^{* * *} p<0.001$ for EPSCS at time point $2^{\prime}$ versus time point $1{ }^{\prime}$ (SNK test); ${ }^{\# \# ~} p<$

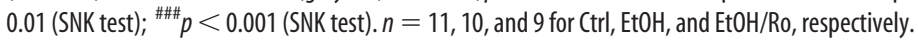

acute ethanol exposure and withdrawal, we first measured the NMDA/AMPA ratio, which detects the relative activity of synaptic NMDARs versus AMPARs (Ungless et al., 2001; Kauer and Malenka, 2007). We found that the NMDA/AMPA ratio is greater in DMS neurons from ethanol-treated slices than from control slices $\left(t_{(17)}=-3.45 ; p<0.01\right.$; Fig. $\left.1 C\right)$, suggesting increased synaptic NMDAR activity and/or decreased synaptic AMPAR function. However, a measurement of AMPARmediated mEPSCs revealed identical amplitudes of the mEPSCs in ethanol-treated slices and controls $\left(t_{(18)}=0.18 ; p>0.05\right.$; Fig. $1 D)$, suggesting that synaptic AMPAR activity is not altered in DMS neurons following acute ethanol treatment. In addition, the unaltered mEPSC frequency $\left(t_{(18)}=0.64 ; p>0.05\right.$; Fig. $\left.1 D\right)$ suggests that the probability of glutamate release is not affected by acute ethanol exposure (Wang et al., 2007). Together, these results show that the activity of synaptic NMDARs, but not synaptic AMPARs, increases following acute ex vivo ethanol exposure and withdrawal.

Acute ex vivo ethanol exposure and withdrawal facilitates the induction of LTP in the DMS

Next, we tested whether the increase in NMDAR activity, induced by acute ethanol exposure and withdrawal, alters the induction of LTP in the DMS. To do so, striatal slices were treated as above with $40 \mathrm{~mm}$ ethanol for $1 \mathrm{~h}$, ethanol was washed out for $30 \mathrm{~min}$, and HFS was delivered to induce LTP of fEPSP/PSs (Yin et al., 2007). As shown in Figure 2, $A$ (top, control; middle, ethanol), $B$ (white circles, control; black circles, ethanol), and $C$ (white bar, control; black bar, ethanol), we found a significant potentiation of the fEPSP/PSs amplitude, measured 20-30 min after HFS, in slices treated previously with ethanol (SNK test; $q=6.10 ; p<$ 0.001 vs baseline), but not in control slices (SNK test; $q=2.04$; $p=0.17$ vs baseline). The analysis of fEPSP/PSs amplitudes by two-way RM-ANOVA further reveals a significant interaction between the HFS and the ethanol treatment $\left(F_{(1,19)}=4.53 ; p<\right.$ $0.05)$. Post hoc comparison by SNK tests shows that fEPSP/PSs amplitudes are significantly different between the control and ethanol groups during the LTP phase $(q=4.26$; $p<0.01$; Fig. $2 C)$. These results suggest that acute ex vivo ethanol exposure and withdrawal facilitates the induction of LTP in the DMS.
Ex vivo ethanol-mediated facilitation of LTP induction in the DMS requires activation of NR2B-NMDARs

We found previously that the ethanol withdrawal-induced increase in NMDAR activity is mediated by the NR2B-NMDARs (Wang et al., 2007, 2010a, 2011). Thus, we examined whether NR2B is required for the ethanol-mediated facilitation of LTP induction. Striatal slices from Sprague Dawley rats were acutely exposed to, and withdrawn from, ethanol, and HFS was delivered in the presence of the NR2B-NMDAR antagonist Ro 25-6981. As shown in Figure 2, $A$ (middle, ethanol; bottom, ethanol/Ro), $B$ (black circles, ethanol; black triangles, ethanol/Ro), and $C$ (black bar, ethanol; gray bar, ethanol/Ro), HFS fails to induce a potentiation of fEPSP/PSs in the presence of Ro 25-6981 (SNK test; $q=$ $1.24 ; p=0.39$ vs baseline). The two-way RM-ANOVA analysis of fEPSP/PSs amplitudes in slices treated with Ro 25-6981 or vehicle reveals a significant interaction between the HFS and the Ro 256981 treatment $\left(F_{(1,17)}=9.41 ; p<0.01\right)$. Post hoc comparison by SNK tests reveals that the normalized amplitude of fEPSP/PSs 20-30 min after HFS are significantly less in the Ro 25-6981treated group than in the controls $(q=6.14 ; p<0.001$; Fig. $2 C)$. These results suggest that acute ex vivo ethanol-mediated facilitation of LTP induction requires activation of NR2B-NMDARs.

\section{Repeated in vivo administration of ethanol induces an NR2B-NMDAR-dependent facilitation of LTP in the DMS}

Previously, we showed that repeated daily systemic administration of ethanol ( $2 \mathrm{~g} / \mathrm{kg}$, i.p.) produces a long-lasting upregulation of NMDAR function in the DMS, which is observed even $16 \mathrm{~h}$ after the last ethanol exposure (Wang et al., 2010a). We used the same procedure to determine whether in vivo ethanol exposure and withdrawal facilitates LTP induction in this brain region. Sprague Dawley rats were systemically treated with ethanol (2 $\mathrm{g} / \mathrm{kg}$, i.p.) or saline for 7 successive days, and LTP was measured in DMS slices prepared $16 \mathrm{~h}$ after the last ethanol administration. As shown in Figure 3, HFS induced a significant increase in LTP of fEPSP/PSs in slices from ethanol-treated rats (SNK test; $q=$ 6.64; $p<0.001$ vs baseline), but not in slices from saline-treated animals (SNK test; $q=2.04 ; p=0.17$ vs baseline). Post hoc SNK tests show that the amplitude of fEPSP/PSs during the LTP phase is significantly higher in the ethanol group than in the control 
group $(q=5.28 ; p<0.001$; Fig. $3 B)$. These results indicate that repeated cycles of in vivo ethanol exposure and withdrawal facilitate the induction of LTP in the DMS.

To confirm that the NR2B-NMDAR is also required for the in vivo ethanolmediated facilitation of LTP, rats received systemic administrations of ethanol or saline once a day for 7 consecutive days, and striatal slices were prepared $16 \mathrm{~h}$ after the last treatment. HFS was then delivered in the presence of Ro 25-6981. As shown in Figure 3, HFS fails to induce LTP in the presence of Ro 25-6981 (SNK test; $q=$ $0.33 ; p=0.82$ vs baseline). SNK Post hoc tests show that the normalized amplitude of fEPSP/PSs 20-30 min after HFS are significantly less in the Ro 25-6981 group than in the control $(q=6.50 ; p<0.001$; Fig. $3 B$ ). Together, these results suggest that activation of NR2B-NMDARs mediates the facilitation of LTP induction in the DMS upon ethanol exposure and withdrawal.

\section{Repeated systemic administration of ethanol and excessive ethanol intake produce a long-lasting increase in the protein levels of synaptic AMPAR subunits in the DMS}

Next, we set out to determine the molecular mechanism that may underlie the ethanol-mediated facilitation of LTP. Activation of NMDARs during LTP induction causes the insertion of new AMPARs from intracellular compartments into the synaptic membranes, leading to synaptic strengthening, e.g., expression of LTP (Malinow and Malenka, 2002; Kerchner and Nicoll, 2008; Ho et al., 2011). We hypothesized that one of the consequences of in vivo ethanol-mediated increases in NMDAR activity is the increase of membranal insertion of AMPARs in the DMS. To test this possibility, we first examined whether repeated systemic administration of ethanol leads to increased synaptic localization of AMPARs in the DMS. We used the same procedure of repeated daily systemic administration of Sprague Dawley rats with ethanol $(2 \mathrm{~g} / \mathrm{kg}$, i.p. $)$ or vehicle as described above. The levels of two major striatal AMPAR subunits, GluR1 and GluR2, were measured in total homogenates and in synaptosomal membranes $16 \mathrm{~h}$ after the last ethanol or vehicle treatment. We found that the immunoreactivities of GluR1 and GluR2 subunits were significantly higher in the synaptosomal fractions, but not in the total homogenates, of the DMS from ethanoltreated rats than those from saline-treated animals (synaptosomal GluR1, $t_{(4)}=-2.92, p<0.05$; synaptosomal GluR2, $t_{(4)}=$ $-3.07, p<0.05$; total GluR1, $t_{(4)}=0.70, p>0.05$; total GluR2, $t_{(4)}=$ $0.55, p>0.05$; Fig. $4 A$ ). These results suggest that repeated systemic administration of ethanol leads to a long-lasting increase in the synaptic localization of the GluR1 and GluR2 subunit-containing AMPARs in the DMS.

Next, we examined whether a similar increase in the synaptic levels of GluR1 and/or GluR2 AMPAR subunits can also be the consequence of cycles of excessive ethanol intake and withdrawal. Using the intermittent access two-bottle choice drinking procedure, Long-Evans rats underwent repeated cycles of excessive consumption of $20 \%$ ethanol, resulting in an average consumption of $6 \mathrm{~g} / \mathrm{kg}$ per $24 \mathrm{~h}$ (Wang et al., 2010a). The DMS tissues were dissected out $1 \mathrm{~d}$ after the completion of the last ethanol-drinking session, and the protein levels of GluR1 and GluR2 were assessed.
Similar to the results obtained after repeated systemic administration of ethanol, the synaptosomal but not the total protein levels of GluR1 and GluR2 subunits are increased in rats with a history of repeated cycles of excessive ethanol intake and withdrawal compared to those consuming water only (synaptosomal GluR1, $t_{(8)}$ $=-2.60, p<0.05$; synaptosomal GluR2, $t_{(12)}=-2.69, p<0.05$; total GluR1, $t_{(11)}=0.76, p>0.05$; total GluR2, $t_{(13)}=1.36, p>0.05$; Fig. $4 B$ ). These results indicate that repeated cycles of excessive ethanol intake and withdrawal cause a long-lasting alteration in the synaptic localization of AMPARs in the DMS.

\section{Inhibition of AMPAR activity in the DMS reduces operant self-administration of ethanol but not of sucrose}

Finally, we examined the hypothesis that the increase in the synaptic localization of AMPAR subunits and the facilitation of LTP upon repeated cycles of excessive ethanol intake and withdrawal may drive ethanol-drinking and ethanol-seeking behaviors. To do so, Long-Evans rats underwent an intermittent-access twobottle choice drinking procedure for 6 weeks and were trained to self-administer ethanol in an operant self-administration procedure, in which lever presses resulted in presentation of a solution of $20 \%$ ethanol (Wang et al., 2010a). After reaching a stable level of ethanol intake ( $\sim 1 \mathrm{~g} / \mathrm{kg}$ per $30 \mathrm{~min})$, the AMPAR antagonist, NBQX, or vehicle was infused into the DMS 15 min before a 30 min session of operant self-administration and lever responding for ethanol was examined. One-way RM-ANOVA analysis showed a significant main effect of NBQX on operant responding for ethanol $\left(F_{(2,12)}=7.58 ; p<0.01\right)$ and on ethanol intake $\left(F_{(2,12)}=9.45 ; p<\right.$ $0.01)$. Post hoc SNK tests further revealed that infusion of NBQX in the DMS significantly reduces the number of lever presses for etha$\operatorname{nol}(0.2 \mu \mathrm{g} / \mu \mathrm{l}, q=4.51, p<0.01 ; 2 \mu \mathrm{g} / \mu \mathrm{l}, q=4.99, p<0.01$; Fig. $5 A a)$ and the levels of ethanol intake $(0.2 \mu \mathrm{g} / \mu \mathrm{l}, q=4.96, p<0.01$; $2 \mu \mathrm{g} / \mu \mathrm{l}, q=5.62, p<0.01$; Fig. 5Ab).

We further measured lever-press responding for a non-drug reinforcing substance, sucrose, after an intra-DMS infusion of NBQX. This experiment was conducted to verify that the inhibitory effect of NBQX on ethanol self-administration is not due to locomotor deficits, and to determine whether the action of the inhibitor in the DMS is specific for ethanol or due to a reduction of general instrumental learning and motivational processes. To 

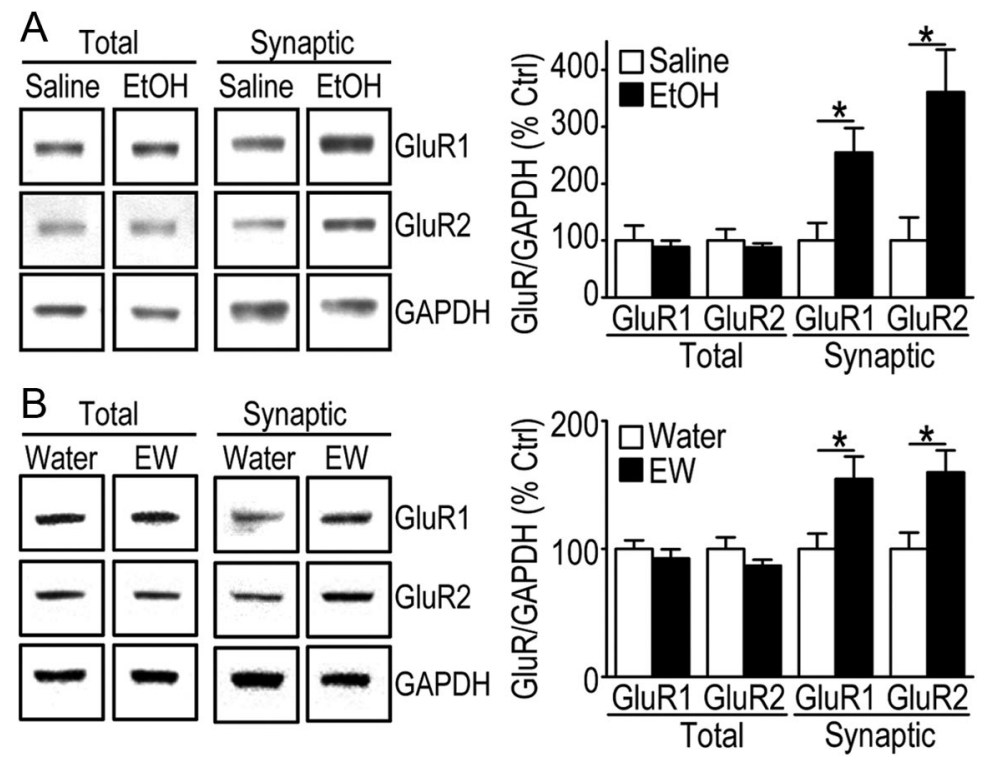

Figure 4. Repeated systemic ethanol administration and excessive ethanol intake upregulate the protein levels of synaptic AMPAR subunits in the DMS. A, Repeated systemic administration of ethanol upregulates the protein levels of synaptic AMPARs. Sprague Dawley rats were systemically administered ethanol or saline once a day for 7 successive days. DMS tissues were dissected out $16 \mathrm{~h}$ after the seventh administration, and GluR1 and GluR2 levels in total homogenates (Total) and at synaptosomal membranes (Synaptic) were measured by Western blot. Left, Sample images of total and synaptosomal protein levels of GluR1 and GluR2. Right, Bar graph summarizing mean protein levels of GluR1 and GluR2 in saline- and ethanol-treated animals. $n=3$ for each group. B, Excessive ethanol intake upregulates synaptic GluR1 and GluR2 subunits of AMPARs. Long-Evans rats underwent an intermittent-access to $20 \%$ ethanol in a two-bottle choice drinking procedure for $7-8$ weeks, DMS tissues were dissected $1 \mathrm{~d}$ after the last ethanol drinking session [ethanol withdrawal (EW)], and protein levels of GluR1 and GluR2 in total homogenates and synaptosomal membranes were measured. Left, Sample images of total and synaptosomal protein levels of GluR1 and GluR2. Right, Average of protein levels of GluR1 and GluR2 subunits in water controls (Water) and ethanol-treated animals. $n=7$ (water) and 6 (EW) for total GluR1; 7 (water) and 8 (EW) for total GluR2; 5 (water) and 5 (EW) for synaptic GluR1, and 7 (water) and 7 (EW) for synaptic GluR2. ${ }^{*} p<0.05$.

do so, rats were trained to self-administer a $1.5 \%$ sucrose solution (Wang et al., 2010a), and 15 min before the testing session, NBQX or vehicle was infused into the DMS. As shown in Figure $5 B$, intra-DMS infusion of NBQX did not significantly alter lever presses for sucrose: one-way RM-ANOVA analysis showed no main effect of NBQX on operant responding for sucrose $\left(F_{(2,15)}=\right.$ $0.11 ; p=0.9)$. This result suggests that NBQX does not alter locomotor activity or general reward-motivated behaviors. Together, these results indicate that the ethanol-mediated increase in the activity of AMPARs in the DMS is required for selfadministration of ethanol.

\section{Discussion}

In the present study we demonstrate that both ex vivo and repeated cycles of in vivo ethanol exposure and withdrawal facilitate the induction of LTP in the DMS in an NR2B-NMDARdependent manner. Consistent with the concept that LTP is mediated by the insertion of AMPARs into the synaptic membranes, we found that both repeated systemic administration of ethanol and excessive ethanol intake cause a long-lasting increase in synaptic AMPAR levels. Importantly, we show that inhibition of AMPARs in the DMS significantly attenuates operant self-administration of ethanol, but not of sucrose. Together, these results indicate that the ethanol-mediated increase in NMDAR activity in the DMS leads to the insertion of AMPARs into the synaptic sites and thus expression of LTP, which, in turn, contributes to the expression and/or the maintenance of excessive ethanol-drinking behaviors.
Ethanol exposure and withdrawal facilitates the induction of LTP in the DMS in an NR2B-NMDAR-dependent manner

Here we show that LTP is facilitated in the DMS following ethanol exposure and withdrawal, whereas Yin et al. (2007) reported that LTP in the DMS is inhibited in the presence of ethanol. The difference between these results may stem from the distinct time points at which LTP is induced. When HFS is delivered in the presence of ethanol, LTP is inhibited (Yin et al., 2007), whereas when HFS is delivered after ethanol withdrawal, LTP is facilitated. Thus, the timing of LTP induction is crucial as the NMDAR activity in DMS neurons is suppressed in the presence of ethanol (Yin et al., 2007; Wang et al., 2010a) and is enhanced after ethanol is withdrawn (Wang et al., 2007; Wang et al., 2010a, 2011; present study). Furthermore, similar enhancement of NMDAR activity in response to ethanol was reported in other brain regions (Yaka et al., 2003; Hendricson et al., 2007; Kash et al., 2009). Since NMDAR activity is required for LTP induction in the DMS (Calabresi et al., 1992; Partridge et al., 2000; Shen et al., 2008), the direct suppression of NMDAR activity by ethanol leads to LTP inhibition, whereas the enhancement of NMDAR activity by ethanol withdrawal causes LTP facilitation. Thus, it is very plausible that both mechanisms occur at different time points of ethanol exposure and withdrawal, and that our results provide an additional perspective of plasticity mechanisms that occur in the DMS long after ethanol is metabolized.

It is also plausible that the facilitation of NMDAR activity in response to ethanol exposure and withdrawal is a homeostatic mechanism that counteracts the inhibitory actions of ethanol on the activity of the NMDAR. This conclusion stems from our previous findings suggesting that the molecular changes leading to Fyn activation occur while ethanol is on board. Specifically, we found that Fyn is activated and NR2B is phosphorylated in hippocampal and striatal slices acutely treated with ethanol (Yaka et al., 2003; Wang et al., 2007). We further showed that the activation of Fyn in response to ethanol results from the release of Fyn from the inhibitory scaffolding protein RACK1 and to the colocalization with protein tyrosine phosphatase alpha, which also occurs in the presence of ethanol (Yaka et al., 2003; Wang et al., 2007; Gibbs et al., 2011). In the DMS, Fyn activation and NR2B phosphorylation are long-lasting and continue after ethanol is no longer on board (Wang et al., 2010a), resulting in the consequent changes in NMDAR and AMPAR activities.

In the present study, we found that ethanol exposure and withdrawal induces facilitation of LTP, which is abolished by the NR2B-NMDAR antagonist Ro 25-6981. These results suggest that ethanol treatments facilitate LTP induction via the upregulation of NR2B-NMDAR activity. This finding is in line with the notion that the NR2B/NR2A ratio controls the threshold for inducing LTP (Yashiro and Philpot, 2008). Compared to NR2Acontaining NMDARs (NR2A-NMDARs), NR2B-NMDARs medi- 


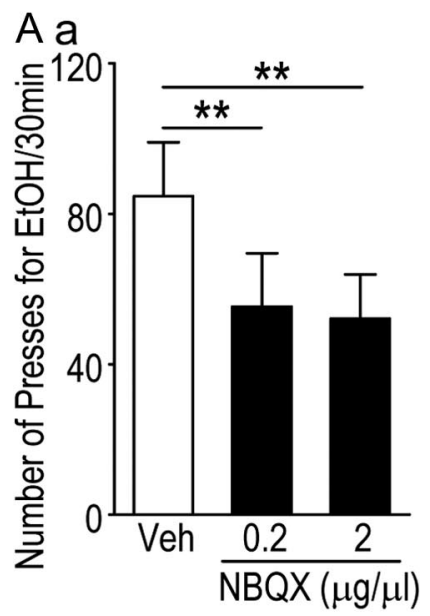

$\mathrm{B}$ a

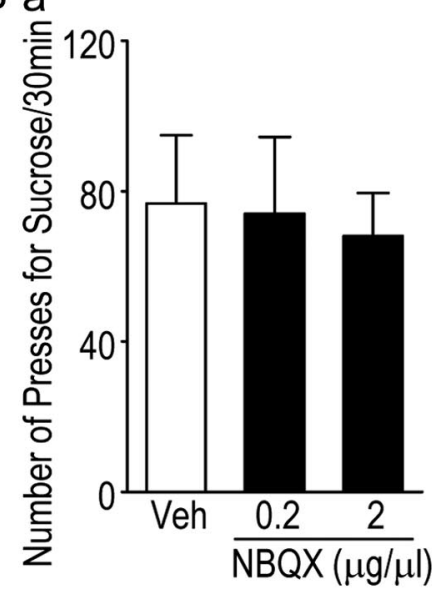

b

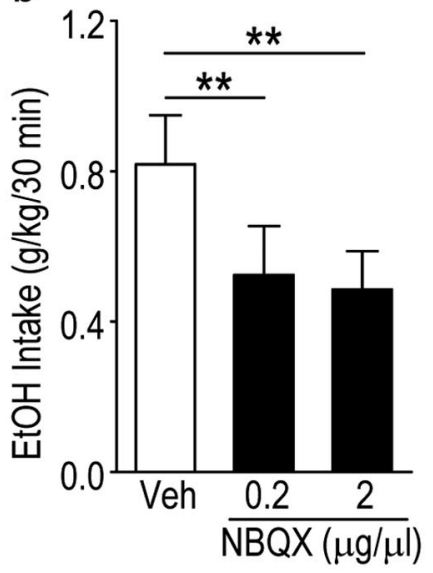

b
C

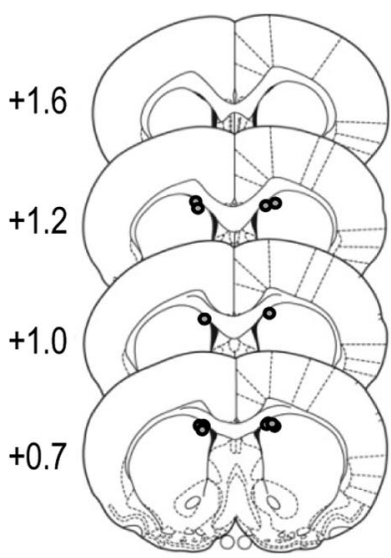

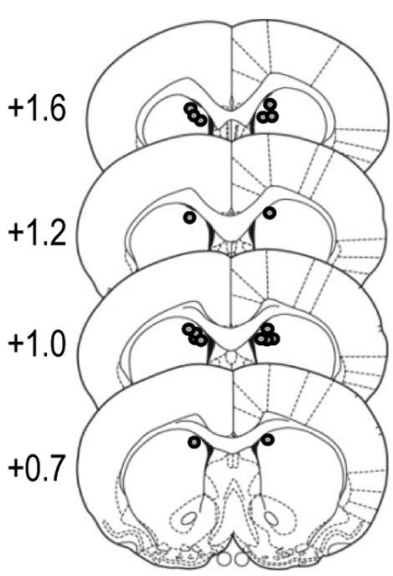

Figure 5. Inhibition of AMPARs reduces operant self-administration of ethanol, but not of sucrose in the DMS. Aa-Ac, Mean \pm SEM of the number of lever presses for ethanol after intra-DMS infusion of vehicle or NBQX $(\boldsymbol{A a})$ and mean \pm SEM of ethanol intake $(\boldsymbol{A b})$ in rats trained on a FR3 schedule to obtain $0.1 \mathrm{ml}$ of a $20 \%$ ethanol solution per delivery during a 30 min session. $A \boldsymbol{c}$, Schematic representation of cannulae placements (gray circles) in coronal sections from the ethanol self-administration experiments. ${ }^{* *} p<0.01$ (SNK test). $n=7$ for each group. Ba, Mean \pm SEM of the number of lever presses for sucrose after intra-DMS infusion of vehicle or NBQX. B $\boldsymbol{b}$, Schematic representation of cannulae placements (gray circles) in coronal sections from the sucrose self-administration experiments. $n=9$ for each group.

ate longer currents (Monyer et al., 1994), carry more $\mathrm{Ca}^{2+}$ per unit of current (Sobczyk et al., 2005), and bind preferentially with CaMKII (Strack and Colbran, 1998; Leonard et al., 1999), which allows CaMKII to remain active even after dissociation from $\mathrm{Ca}^{2+} / \mathrm{cal}$ modulin (Bayer et al., 2001; Lisman et al., 2012) and is required for LTP induction (Barria and Malinow, 2005; Zhou et al., 2007; Foster et al., 2010). Previously, we found that the activity of NR2B- but not NR2A-NMDARs increases following ethanol exposure and withdrawal (Wang et al., 2007, 2010a, 2011), which indicates an elevated $\mathrm{NR} 2 \mathrm{~B} / \mathrm{NR} 2 \mathrm{~A}$ ratio in response to this ethanol treatment that is likely to underlie the facilitation of LTP. The NR2B-NMDAR-dependent facilitation of LTP in response to ethanol exposure and withdrawal was observed recently in the bed nucleus of the stria terminalis (BNST) (Wills et al., 2012). Interestingly, the LTP facilitation in the BNST was thought to be mediated by the increased lateral movement of NR2B-NMDARs from the synaptic to extrasynaptic sites (Wills et al., 2012), whereas we show that LTP facilitation in the DMS is likely to be mediated by the increased forward trafficking of NR2BNMDAR from the cytoplasmic into the synaptic membrane. This conclusion stems from the observation that the $7 \mathrm{~d}$ systemic administration of ethanol increases the synaptic but not total protein levels of NR2B-NMDARs in the DMS (Wang et al., 2010a, 2011). The difference in the mechanisms underlying ethanol-induced LTP may result from the diverse responses of NMDARs to ethanol exposure in these two brain regions. For example, acute ethanol exposure fails to inhibit NMDAR activity in the presence of Ro 25-6981 in the BNST (Wills et al., 2012), whereas we found that such inhibition is preserved in the DMS (Wang et al., 2007). Importantly, in the present study we provide evidence to suggest that the mechanism underlying the LTP facilitation in the DMS is associated with enhancement of GluR1 and GluR2 subunits of AMPARs into the synaptic membrane (see below).

Repeated systemic administration of ethanol and excessive ethanol consumption upregulate synaptic AMPAR levels

We found that repeated systemic ethanol administration, as well as ethanol withdrawal in rats with a history of excessive ethanol intake, leads to an increased trafficking of AMPARs from the cytoplasmic into synaptic sites. Insertion of new AMPARs is thought to underlie LTP (Malinow and Malenka, 2002; Kerchner and Nicoll, 2008). Thus, the increased insertion of AMPARs in the DMS synapses following in vivo ethanol exposure and withdrawal is likely a consequence of the facilitation of LTP. Importantly, the ethanol-mediated synaptic AMPAR change is also long-lasting: it is observed $24 \mathrm{~h}$ after withdrawal from excessive ethanol intake.

Surprisingly, we did not observe occlusion of LTP induction in response to ethanol exposure and withdrawal. However, LTP occlusion normally requires prolonged stimulation of a synapse 
to induce the saturation of LTP, which prevents further LTP induction by a second stimulation of the same synapse (Lledo et al., 1995). Thus, it is likely that the ethanol exposure procedure used in the present study does not induce a maximal NMDARdependent LTP.

We observed that although the synaptic levels of AMPAR GluR1 and GluR2 subunits are increased following repeated in vivo ethanol administration, AMPAR function, as measured by AMPA-induced currents and by the amplitude of AMPARmEPSCs, remains unchanged after acute ex vivo ethanol exposure and withdrawal. The difference between the electrophysiological and biochemical data is likely derived from the degree of synaptic activity in the DMS ex vivo versus in vivo. Striatal neurons, including the DMS, receive glutamatergic inputs from neurons outside of the striatum (Kreitzer and Malenka, 2008). The neural connections between the somata of these presynaptic neurons, such as cortical pyramidal cells, and DMS neurons are in large part removed in coronal sections used in this study, which leads to dramatically reduced synaptic activity (Smeal et al., 2007). As a result, the activity-dependent plasticity of AMPARs is substantially reduced in DMS slices, leading to little alteration of AMPAR subunit levels in response to ethanol exposure and withdrawal. In vivo, however, the intact network allows abundant firing activity of presynaptic neurons to evoke synaptic transmission in the DMS, leading to activity-dependent plasticity of AMPARs. In ethanol-treated rats (repeated systemic administration or consumption), the enhanced NMDAR function results in AMPAR insertion into synaptic sites.

\section{AMPAR activity in the DMS is required for the expression and/or maintenance of excessive ethanol consumption}

As discussed above, in vivo ethanol exposure and withdrawal causes an increase in synaptic localization of AMPARs and an increase in NR2B-NMDAR-dependent LTP in the DMS. AMPARs mediate LTP of fast synaptic transmission, and we provide evidence suggesting that the enhancement of NMDARs and AMPARs leading to synaptic plasticity indeed have functional behavioral consequences. Specifically, we showed previously that intra-DMS infusion of the NR2B-NMDARs inhibitor ifenprotil reduces ethanol self-administration (Wang et al., 2010a), and here we show that the inhibition of AMPARs by NBQX in the DMS of rats attenuates ethanol self-administration. Given that the DMS is required for the acquisition and expression of goaldirected behaviors (Yin and Knowlton, 2006), the increased synaptic localization of AMPARs and consequent aberrant LTP may strengthen action-outcome association, thereby enhancing the propensity to engage in an ethanol-seeking and ethanol-taking response that may underlie the development and maintenance of excessive ethanol consumption. Breaking the action-outcome association by inhibition of AMPAR activity in the DMS may prevent ethanol-seeking and ethanol-drinking behaviors. In fact, here we show that inhibition of AMPARs by NBQX in the DMS of rats with a history of excessive ethanol intake preferentially attenuates operant ethanol self-administration.

In summary, our results suggest that NMDAR-dependent LTP of AMPAR activity in the DMS is facilitated by cycles of excessive ethanol intake and withdrawal, and this aberrant plasticity may contribute to long-lasting neuroadaptations that are associated with pathological ethanol-related behaviors such as the development and maintenance of excessive ethanol drinking.

\section{References}

Barria A, Malinow R (2005) NMDA receptor subunit composition controls synaptic plasticity by regulating binding to CaMKII. Neuron 48:289-301. CrossRef Medline

Bateup HS, Santini E, Shen W, Birnbaum S, Valjent E, Surmeier DJ, Fisone G, Nestler EJ, Greengard P (2010) Distinct subclasses of medium spiny neurons differentially regulate striatal motor behaviors. Proc Natl Acad Sci U S A 107:14845-14850. CrossRef Medline

Bayer KU, De Koninck P, Leonard AS, Hell JW, Schulman H (2001) Interaction with the NMDA receptor locks CaMKII in an active conformation. Nature 411:801-805. CrossRef Medline

Belin D, Jonkman S, Dickinson A, Robbins TW, Everitt BJ (2009) Parallel and interactive learning processes within the basal ganglia: relevance for the understanding of addiction. Behav Brain Res 199:89-102. CrossRef Medline

Beutler LR, Wanat MJ, Quintana A, Sanz E, Bamford NS, Zweifel LS, Palmiter RD (2011) Balanced NMDA receptor activity in dopamine D1 receptor (D1R)- and D2R-expressing medium spiny neurons is required for amphetamine sensitization. Proc Natl Acad Sci U S A 108:4206-4211. CrossRef Medline

Bliss TV, Collingridge GL (1993) A synaptic model of memory: long-term potentiation in the hippocampus. Nature 361:31-39. CrossRef Medline

Borgland SL, Taha SA, Sarti F, Fields HL, Bonci A (2006) Orexin A in the VTA is critical for the induction of synaptic plasticity and behavioral sensitization to cocaine. Neuron 49:589-601. CrossRef Medline

Calabresi P, Pisani A, Mercuri NB, Bernardi G (1992) Long-term potentiation in the striatum is unmasked by removing the voltage-dependent magnesium block of NMDA receptor channels. Eur J Neurosci 4:929935. CrossRef Medline

Corbit LH, Janak PH (2010) Posterior dorsomedial striatum is critical for both selective instrumental and Pavlovian reward learning. Eur J Neurosci 31:1312-1321. CrossRef Medline

Durieux PF, Bearzatto B, Guiducci S, Buch T, Waisman A, Zoli M, Schiffmann SN, de Kerchove d'Exaerde A (2009) D2R striatopallidal neurons inhibit both locomotor and drug reward processes. Nat Neurosci 12:393395. CrossRef Medline

Ferguson SM, Eskenazi D, Ishikawa M, Wanat MJ, Phillips PE, Dong Y, Roth BL, Neumaier JF (2011) Transient neuronal inhibition reveals opposing roles of indirect and direct pathways in sensitization. Nat Neurosci 14:22-24. CrossRef Medline

Foster KA, McLaughlin N, Edbauer D, Phillips M, Bolton A, ConstantinePaton M, Sheng M (2010) Distinct roles of NR2A and NR2B cytoplasmic tails in long-term potentiation. J Neurosci 30:2676-2685. CrossRef Medline

Gerdeman GL, Partridge JG, Lupica CR, Lovinger DM (2003) It could be habit forming: drugs of abuse and striatal synaptic plasticity. Trends Neurosci 26:184-192. CrossRef Medline

Gibb SL, Hamida SB, Lanfranco MF, Ron D (2011) Ethanol-induced increase in Fyn kinase activity in the dorsomedial striatum is associated with subcellular redistribution of protein tyrosine phosphatase alpha. J Neurochem 119:879-889. CrossRef Medline

Graybiel AM, Aosaki T, Flaherty AW, Kimura M (1994) The basal ganglia and adaptive motor control. Science 265:1826-1831. CrossRef Medline

Hendricson AW, Maldve RE, Salinas AG, Theile JW, Zhang TA, Diaz LM, Morrisett RA (2007) Aberrant synaptic activation of N-methyl-D-aspartate receptors underlies ethanol withdrawal hyperexcitability. J Pharmacol Exp Ther 321:60-72. CrossRef Medline

Hikida T, Kimura K, Wada N, Funabiki K, Nakanishi S (2010) Distinct roles of synaptic transmission in direct and indirect striatal pathways to reward and aversive behavior. Neuron 66:896-907. CrossRef Medline

Ho VM, Lee JA, Martin KC (2011) The cell biology of synaptic plasticity. Science 334:623-628. CrossRef Medline

Hyman SE, Malenka RC, Nestler EJ (2006) Neural mechanisms of addiction: the role of reward-related learning and memory. Annu Rev Neurosci 29:565-598. CrossRef Medline

Jeanes ZM, Buske TR, Morrisett RA (2011) In vivo chronic intermittent ethanol exposure reverses the polarity of synaptic plasticity in the nucleus accumbens shell. J Pharmacol Exp Ther 336:155-164. CrossRef Medline

Kalivas PW, O'Brien C (2008) Drug addiction as a pathology of staged neuroplasticity. Neuropsychopharmacology 33:166-180. CrossRef Medline Kang-Park MH, Kieffer BL, Roberts AJ, Siggins GR, Moore SD (2007) Pre- 
synaptic delta opioid receptors regulate ethanol actions in central amygdala. J Pharmacol Exp Ther 320:917-925. Medline

Kash TL, Baucum AJ 2nd, Conrad KL, Colbran RJ, Winder DG (2009) Alcohol exposure alters NMDAR function in the bed nucleus of the stria terminalis. Neuropsychopharmacology 34:2420-2429. CrossRef Medline

Kauer JA, Malenka RC (2007) Synaptic plasticity and addiction. Nat Rev Neurosci 8:844-858. CrossRef Medline

Kerchner GA, Nicoll RA (2008) Silent synapses and the emergence of a postsynaptic mechanism for LTP. Nat Rev Neurosci 9:813-825. CrossRef Medline

Kreitzer AC, Malenka RC (2008) Striatal plasticity and basal ganglia circuit function. Neuron 60:543-554. CrossRef Medline

Leonard AS, Lim IA, Hemsworth DE, Horne MC, Hell JW (1999) Calcium/ calmodulin-dependent protein kinase II is associated with the N-methylD-aspartate receptor. Proc Natl Acad Sci U S A 96:3239-3244. CrossRef Medline

Lisman J, Yasuda R, Raghavachari S (2012) Mechanisms of CaMKII action in long-term potentiation. Nat Rev Neurosci 13:169-182. CrossRef Medline

Lledo PM, Hjelmstad GO, Mukherji S, Soderling TR, Malenka RC, Nicoll RA (1995) Calcium/calmodulin-dependent kinase II and long-term potentiation enhance synaptic transmission by the same mechanism. Proc Natl Acad Sci U S A 92:11175-11179. CrossRef Medline

Lobo MK, Covington HE 3rd, Chaudhury D, Friedman AK, Sun H, DamezWerno D, Dietz DM, Zaman S, Koo JW, Kennedy PJ, Mouzon E, Mogri M, Neve RL, Deisseroth K, Han MH, Nestler EJ (2010) Cell type-specific loss of BDNF signaling mimics optogenetic control of cocaine reward. Science 330:385-390. CrossRef Medline

Lüscher C, Malenka RC (2011) Drug-evoked synaptic plasticity in addiction: from molecular changes to circuit remodeling. Neuron 69:650-663. CrossRef Medline

Malenka RC, Nicoll RA (1999) Long-term potentiation-a decade of progress? Science 285:1870-1874. CrossRef Medline

Malinow R, Malenka RC (2002) AMPA receptor trafficking and synaptic plasticity. Annu Rev Neurosci 25:103-126. CrossRef Medline

McCool BA (2011) Ethanol modulation of synaptic plasticity. Neuropharmacology 61:1097-1108. CrossRef Medline

Monyer H, Burnashev N, Laurie DJ, Sakmann B, Seeburg PH (1994) Developmental and regional expression in the rat brain and functional properties of four NMDA receptors. Neuron 12:529-540. CrossRef Medline

Partridge JG, Tang KC, Lovinger DM (2000) Regional and postnatal heterogeneity of activity-dependent long-term changes in synaptic efficacy in the dorsal striatum. J Neurophysiol 84:1422-1429. Medline

Paxinos G, Watson C (2007) The rat brain in stereotaxic coordinates, Ed 7. San Diego: Academic.

Russo SJ, Dietz DM, Dumitriu D, Morrison JH, Malenka RC, Nestler EJ (2010) The addicted synapse: mechanisms of synaptic and structural plasticity in nucleus accumbens. Trends Neurosci 33:267-276. CrossRef Medline

Schotanus SM, Chergui K (2008) Long-term potentiation in the nucleus accumbens requires both NR2A- and NR2B-containing N-methyl-Daspartate receptors. Eur J Neurosci 27:1957-1964. CrossRef Medline

Shen W, Flajolet M, Greengard P, Surmeier DJ (2008) Dichotomous dopaminergic control of striatal synaptic plasticity. Science 321:848-851. CrossRef Medline

Smeal RM, Gaspar RC, Keefe KA, Wilcox KS (2007) A rat brain slice prep- aration for characterizing both thalamostriatal and corticostriatal afferents. J Neurosci Methods 159:224-235. CrossRef Medline

Sobczyk A, Scheuss V, Svoboda K (2005) NMDA receptor subunitdependent $\left[\mathrm{Ca}^{2+}\right]$ signaling in individual hippocampal dendritic spines. J Neurosci 25:6037-6046. CrossRef Medline

Strack S, Colbran RJ (1998) Autophosphorylation-dependent targeting of calcium/ calmodulin-dependent protein kinase II by the NR2B subunit of the N-methyl-D-aspartate receptor. J Biol Chem 273:20689-20692. CrossRef Medline

Ungless MA, Whistler JL, Malenka RC, Bonci A (2001) Single cocaine exposure in vivo induces long-term potentiation in dopamine neurons. Nature 411:583-587. CrossRef Medline

Voorn P, Vanderschuren LJ, Groenewegen HJ, Robbins TW, Pennartz CM (2004) Putting a spin on the dorsal-ventral divide of the striatum. Trends Neurosci 27:468-474. CrossRef Medline

Wang J, Carnicella S, Phamluong K, Jeanblanc J, Ronesi JA, Chaudhri N, Janak PH, Lovinger DM, Ron D (2007) Ethanol induces long-term facilitation of NR2B-NMDA receptor activity in the dorsal striatum: implications for alcohol drinking behavior. J Neurosci 27:3593-3602. CrossRef Medline

Wang J, Lanfranco MF, Gibb SL, Yowell QV, Carnicella S, Ron D (2010a) Long-lasting adaptations of the NR2B-containing NMDA receptors in the dorsomedial striatum play a crucial role in alcohol consumption and relapse. J Neurosci 30:10187-10198. CrossRef Medline

Wang J, Carnicella S, Ahmadiantehrani S, He DY, Barak S, Kharazia V, Ben Hamida S, Zapata A, Shippenberg TS, Ron D (2010b) Nucleus accumbensderived glial cell line-derived neurotrophic factor is a retrograde enhancer of dopaminergic tone in the mesocorticolimbic system. J Neurosci 30:14502-14512. CrossRef Medline

Wang J, Lanfranco MF, Gibb SL, Ron D (2011) Ethanol-mediated longlasting adaptations of the NR2B-containing NMDA receptors in the dorsomedial striatum. Channels (Austin) 5:205-209. CrossRef Medline

Wills TA, Klug JR, Silberman Y, Baucum AJ, Weitlauf C, Colbran RJ, Delpire E, Winder DG (2012) GluN2B subunit deletion reveals key role in acute and chronic ethanol sensitivity of glutamate synapses in bed nucleus of the stria terminalis. Proc Natl Acad Sci U S A 109:E278-E287.

Xiao C, Shao XM, Olive MF, Griffin WC 3rd, Li KY, Krnjević K, Zhou C, Ye JH (2009) Ethanol facilitates glutamatergic transmission to dopamine neurons in the ventral tegmental area. Neuropsychopharmacology 34:307-318. CrossRef Medline

Yaka R, Phamluong K, Ron D (2003) Scaffolding of Fyn kinase to the NMDA receptor determines brain region sensitivity to ethanol. J Neurosci 23:3623-3632. Medline

Yashiro K, Philpot BD (2008) Regulation of NMDA receptor subunit expression and its implications for LTD, LTP, and metaplasticity. Neuropharmacology 55:1081-1094. CrossRef Medline

Yin HH, Knowlton BJ (2006) The role of the basal ganglia in habit formation. Nat Rev Neurosci 7:464-476. CrossRef Medline

Yin HH, Park BS, Adermark L, Lovinger DM (2007) Ethanol reverses the direction of long-term synaptic plasticity in the dorsomedial striatum. Eur J Neurosci 25:3226-3232. CrossRef Medline

Zhou Y, Takahashi E, Li W, Halt A, Wiltgen B, Ehninger D, Li GD, Hell JW, Kennedy MB, Silva AJ (2007) Interactions between the NR2B receptor and CaMKII modulate synaptic plasticity and spatial learning. J Neurosci 27:13843-13853. CrossRef Medline 